Guest Editorial, part of a Special Feature on Seeking sustainable pathways for land use in Latin America

\title{
Seeking sustainable pathways for land use in Latin America
}

\author{
$\underline{\text { Juan C. Rocha }}^{1,2,3}, \underline{\text { Nestor Mazzeo }}^{2,4}$, Matias Piaggio $^{2,5}$ and $\underline{\text { Miguel Carriquiry }}^{2,6}$
}

Key Words: Latin America; land use change; sustainability; resilience

Achieving sustainable development goals in Latin America, and doing resilience research for that matter, has its own challenges. The Global South is faced with different types of problems, and therefore solutions, in achieving global sustainability ambitions (Nagendra 2018, Nagendra et al. 2018). Although each country has its own particularities, the region shares a recent colonial past that focused on natural resource extraction, weak government institutions that do not prioritize the environment, and in many cases recent dictatorship regimes that have diminished social mobilization toward equity. Not surprisingly, Latin America is a hot spot for environmental conflicts, but also the home of many grass-roots movements that put the environment at the forefront of their agendas (Scheidel et al. 2020).

Within that context, the South American Institute for Resilience and Sustainability Studies (SARAS) gathered international experts in 2016 to investigate the question of seeking sustainable pathways for land use in Latin America. Land as resource, territory, and place defining identity, is at the core of many environmental conflicts. A workshop resulted in a few paper ideas. Ecology and Society gave us the opportunity to extend our endeavor to a larger network of Latin American interested researchers who promptly contributed additional efforts and perspectives. With this special feature, today we celebrate their efforts and dedicate a few pages to resilience research in the Global South.

One of the central concepts in resilience science is the idea of regime shifts, i.e., large, abrupt, and persistent critical transitions in the function and structure of social-ecological systems (Folke et al. 2004, Biggs et al. 2018). Applications of this concept have been disproportionately dominant in ecological sciences, with limited understanding of the social dynamics underlying these regimes (Biggs et al. 2018). Three of our contributions address this gap. Bernardi et al (2019) investigated how the forest to savannas and grasslands transitions in natural grasslands of Uruguay is shaped by land use change over a 45 -year time series (1966-2011), concluding that current land use changes can prevent or facilitate forest transitions and the ecosystem services they provide. Calaboni et al. (2018) studied deforestation and afforestation patterns in Sao Paulo (Brazil). Their 40-year study shows that forest loss is driven by agricultural expansion, but in areas suitable for agriculture, increasing intensification levels allows for forest recovery. The forest dynamics were not only driven by the economic incentives behind agriculture development, but also by competing policies to modernize agriculture on one hand, and protect natural resources on the other. Rocha et al. (2019) studied system archetypes of land use change across seven case studies. By means of causal networks codeveloped with case experts, they found that deforestation, international trade, food demand, commodity prices, and technological change are key drivers of land use change; while rural migration, land pricing and property rights, as well as telecoupling are common causal pathways underlying land use transitions. Similar to Calaboni et al. (2018), Rocha et al. (2019) shows that successful policies are context dependent and in many cases competing political interests can lock land use in particular regimes.

Land use conversion and change reduces biodiversity and leads to redundancy loss affecting the ability of ecosystems to provide some services today and risking additional scarcities into the future. Planning and guiding future land use changes in order to prevent further losses or recover ecosystem services and functions is urgent and a key frontier of research. Identifying sensitive areas in which efforts should be concentrated for maximum impact, and providing guidance on general principles that could help in planning pathways for land uses conducive to sustainable development are necessary steps in this direction. Three contributions can be associated with this endeavor. Brazeiro et al. (2020) analyze biodiversity losses resulting from the expansion of agricultural and commercial (exotic) forest plantations at the expense of grasslands in Uruguay. The authors identify priority areas for conservation based on a method that combines species richness and number of focal/prioritized species that live in grasslands. Projections of land use change under business as usual scenarios allow their method to identify areas at risk of grassland and thus biodiversity losses, as well as to target conservation efforts. A discussion of a more general framework to focalize conservation efforts and in particular in terms of ecosystem configurations, based on principles of resilience thinking (Biggs et al. 2015), is discussed by Ruiz et al. (2020) using the Amazon basin as the subject of analysis. The authors find that historical aspects of Latin America and the Amazon Basin have led to concrete challenges for resilience of the ecosystems, namely natural, cultural, and institutional fragmentation that act as causes and consequences of the patterns of land use observed. Challenges associated with institutional design, effective spaces for the participation of local stakeholders, social learning, and polycentric and adaptive governance are all discussed as major capstones for the advancement of development that is sustainable and resilient. Torrella et al. (2018) developed a modeling tool to assess how multiscale patterns of deforestation and fragmentation impacts forest loss in the Argentinian Chaco. By comparing different deforestation scenarios, they find that implementation

${ }^{1}$ Stockholm Resilience Centre, Stockholm University, Sweden, ${ }^{2}$ South American Institute for Resilience and Sustainability Studies, Uruguay, ${ }^{3}$ Future Earth, Sweden, ${ }^{4}$ Centro Universitario Regional del Este, Universidad de La República, Uruguay, ${ }^{5}$ International Union for the Conservation of Nature, Economics Knowledge Unit, Science and Economics Team, Washington, D.C., USA, ${ }^{6}$ Instituto de Economía, Facultad de Ciencias Económicas y de Administración, Universidad de la República, Uruguay 
of regional corridors and the type of deforestation practices in local plots can increase forest connectivity and avoid the loss of important forest functions and services. Forest fragmentation can be managed and avoided by combining a suit of conservation and forest use activities across regional and local scales.

Deforestation and the associated consequences for the provision of local and global ecosystem services has been a focus of intense and renewed research. There is a large body of research addressing proximate and distal causes of land use change in general and deforestation in particular, analyzing possible strategies to stop or (sometimes) hopefully reverse them. Less attention has been paid to intrinsic drivers or motivations for deforestation. A contribution of this special feature (Rueda et al. 2019) specifically addresses this gap by studying the intrinsic motivations for deforestation using a new instrument based on self-determination theory implemented through a survey on a sample of rural households in Colombia. In particular the sample targeted settlers of an active deforestation frontier. The authors find that intrinsic motivation is positively correlated with less self-reported deforestation. The opposite is observed for unmotivated individuals and for those that would expect payments for conservation. These findings provide relevant information for the design of policies and interventions by better tailoring incentives and motivation for more effectively reducing deforestation.

Traditional ecological knowledge (TEK) is a key component for building adaptive capacity and resilience (Berkes et al. 2003, Biggs et al.2018). Two of our contributions explore its role in the context of agricultural practices in the Amazon. Slash-and-burn shifting cultivation is common in indigenous societies in the Amazon basin (Schritt et al. 2020). The large land use of this farming practice is of increasing concern because of population growth and losses of territory. In this scenario, Schritt et al (2020) evaluate the feasibility of transforming shifting cultivation into a permanent cropping system by application of Terra Preta practice in the Ecuadorian Amazon. They find it is possible to close nutrient cycles locally to generate permanent farmland by combining knowledge and practices of the indigenous communities.

The study of Fonseca-Cepeda et al. (2019) explores the agriculture systems in the Colombian Amazon denominated chagras, a traditional production of indigenous peoples. This ethnographic study reveals several TEK transformations during 1970-2016, particularly changes in land use, temporality of land use, and production diversity. The transformations analyzed demonstrated an important adaptive capacity of the chagra systems in response to social and economic drivers.

Latin America, as in many other parts of the world, is rapidly becoming urban; most of the population today lives in cities. In this context, urbanization continues to drive informal settlement growth on land exposed to hazards (Smith et al. 2020). Medellín (Colombia) is a relevant example for exploring landslide riskreducing strategies for informal settlements from the community and state perspectives, and for understanding the main barriers and identifying viable approaches. Smith et al. (2020) compare two configurations of community-local government for negotiation (Cabildo Abierto and local government-community Working Group). Their main results highlight the relevance of overcoming the state-community stand-off over land occupation rights, by reframing the problem away from conventional longterm land use planning issues toward issues of safety in the short and medium term (involving both community and local government). Greater openness and flexibility emerge as key attributes in the negotiation processes.

Successful management of common resources depends on understanding the political context in which they are managed, their actors, their mental models, and the potential trade-offs or conflict of interest that emerge from different political processes. Two contributions fall within this line of inquiry. Walters et al. (2019) developed a novel method of eliciting mental models from visual boundary objects in social-ecological contexts by combining content analysis with theoretical frameworks for boundary objects and systems thinking. Visual artifacts such as knowledge maps are used in hydropolitical contexts to understand and facilitate discussion across scales about challenges and opportunities from multiple perspectives (Walters et al. 2019). Their framework enables insights into the collective mental models of stakeholders, organizations, and decision-making institutions, and their priorities, vulnerabilities, and adaptation strategies in the case of the Pilcomayo basin. Similarly, the Wallbott et al. (2019) study reveals the opportunities and challenges of current payment for ecosystem services (PES) programs in Costa Rica including the REDD+ approach, by mapping relevant stakeholders with influence on the forestry policy design and implementation. Although Costa Rica is a leader on the implementation of PES and REDD+, challenges remain in how to integrate agriculture and environmental policies for a climate smart landscape planning.

Thanks to the authors' contributions and the dedicated work of the reviewers, this special feature delivers a broad spectrum of topics, problems, methods, and possible solutions to sustainable land use in the Latin American context. We hope the reader finds value and inspiration on that diversity. The 12 papers in this collection advance our understanding of land use regime shifts, land use planning and management, intrinsic causes of deforestation, the role of traditional ecological knowledge as source of adaptive capacity, the challenges of rapid urbanization, as well as the role of mental models on managing transboundary resources. Nobel Prize winner Elinor Ostrom advocated for better understanding of the diversity of social-ecological contexts by reminding us that there are no silver bullet solutions to environmental problems (Ostrom 2007). We hope the papers of this special feature help us recognize and value such diversity of contexts, sustainable solutions, and offer insights for future theory development.

Responses to this article can be read online at: http://www.ecologyandsociety.org/issues/responses. php/11824

\section{Acknowledgments:}

This special feature was supported by the South American Institute of Resilience and Sustainability Studies (SARAS). We thank the authors and reviewers that made this volume possible. 


\section{Data Availability Statement:}

The guest editorial does not include any data or code, there is no new analysis presented.

\section{LITERATURE CITED}

Berkes, F., J. Colding, and C. Folke, editors. 2003. Navigating social-ecological systems: building resilience for complexity and change. Cambridge University Press, Cambridge, UK. https://doi. org/10.1017/CBO9780511541957

Bernardi, R. E., M. Buddeberg, M. Arim, and M. Holmgren. 2019. Forests expand as livestock pressure declines in subtropical South America. Ecology and Society 24(2):19. https://doi. org/10.5751/ES-10688-240219

Biggs, R., G. D. Peterson, and J. Rocha. 2018. The Regime Shifts Database: a framework for analyzing regime shifts in socialecological systems. Ecology and Society 23(3):9. https://doi. org/10.5751/ES-10264-230309

Biggs, R., M. Schlüter, and M. L. Schoon. 2015. Principles for building resilience: sustaining ecosystem services in socialecological systems. Cambridge University Press, Cambridge, UK. https://doi.org/10.1017/CBO9781316014240

Brazeiro, A., M. Achkar, C. Toranza, and L. Bartesaghi. 2020. Agricultural expansion in Uruguayan grasslands and priority areas for vertebrate and woody plant conservation. Ecology and Society 25(1):15. https://doi.org/10.5751/ES-11360-250115

Calaboni, A., L. R. Tambosi, A. T. Igari, J. S. Farinaci, J. P. Metzger, and M. Uriarte. 2018. The forest transition in São Paulo, Brazil: historical patterns and potential drivers. Ecology and Society 23(4):7. https://doi.org/10.5751/ES-10270-230407

Folke, C., S. Carpenter, B. Walker, M. Scheffer, T. Elmqvist, L. Gunderson, and C. S. Holling. 2004. Regime shifts, resilience, and biodiversity in ecosystem management. Annual Review of Ecology, Evolution, and Systematics 35:557-581. https://doi. org/10.1146/annurev.ecolsys.35.021103.105711

Fonseca-Cepeda, V., C. J. Idrobo, and S. Restrepo. 2019. The changing chagras: traditional ecological knowledge transformations in the Colombian Amazon. Ecology and Society 24(1):8. https:// doi.org/10.5751/ES-10416-240108

Nagendra, H. 2018. The global south is rich in sustainability lessons that students deserve to hear. Nature 557:485-488. https:// doi.org/10.1038/d41586-018-05210-0

Nagendra, H., X. Bai, E. S. Brondizio, and S. Lwasa. 2018. The urban south and the predicament of global sustainability. Nature Sustainability 1:341-349. https://doi.org/10.1038/s41893-018-0101-5

Ostrom, E. 2007. A diagnostic approach for going beyond panaceas. Proceedings of the National Academy of Sciences of the United States of America 104(39):15181-15187. https://doi. org/10.1073/pnas.0702288104

Rocha, J. C., M. Baraibar, L. Deutsch, A. de Bremond, J. Oestreicher, F. Rositano, and C. Gelabert. 2019. Toward understanding the dynamics of land change in Latin America: potential utility of a resilience approach for building archetypes of land-systems change. Ecology and Society 24(1):17. https://doi. org/10.5751/ES-10349-240117

Rueda, X., M. A. Velez, L. Moros, and L. A. Rodriguez. 2019. Beyond proximate and distal causes of land-use change: linking individual motivations to deforestation in rural contexts. Ecology and Society 24(1):4. https://doi.org/10.5751/ES-10617-240104

Ruiz Agudelo, C. A., N. Mazzeo, I. Díaz, M. P. Barral, G. Piñeiro, I. Gadino, I. Roche, and R. Acuña. 2020. Land use planning in the Amazon basin: challenges from resilience thinking. Ecology and Society 25(1):8. https://doi.org/10.5751/ES-11352-250108

Scheidel, A., D. Del Bene, J. Liu, G. Navas, S. Mingorría, F. Demaria, S. Avila, B. Roy, I. Ertör, L. Temper, and J. MartínezAlier. 2020. Environmental conflicts and defenders: a global overview. Global Environmental Change 63:102104. https://doi. org/10.1016/j.gloenvcha.2020.102104

Schritt, H., C. Beusch, P. Ríos Guayasamín, and M. Kaupenjohann. 2020. Transformation of traditional shifting cultivation into permanent cropping systems: a case study in Sarayaku, Ecuador. Ecology and Society 25(1):10. https://doi. org/10.5751/ES-11252-250110

Smith, H., F. Coupé, S. Garcia-Ferrari, H. Rivera, and W. E. Castro Mera. 2020. Toward negotiated mitigation of landslide risks in informal settlements: reflections from a pilot experience in Medellín, Colombia. Ecology and Society 25(1):19. https://doi. org/10.5751/ES-11337-250119

Torrella, S. A., M. Piquer-Rodríguez, C. Levers, R. Ginzburg, G. Gavier-Pizarro, and T. Kuemmerle. 2018. Multiscale spatial planning to maintain forest connectivity in the Argentine Chaco in the face of deforestation. Ecology and Society 23(4):37. https:// doi.org/10.5751/ES-10546-230437

Wallbott, L., G. Siciliano, and M. Lederer. 2019. Beyond PES and REDD+: Costa Rica on the way to climate-smart landscape management? Ecology and Society 24(1):24. https://doi. org/10.5751/es-10476-240124

Walters, R. S., E. S. Kenzie, A. E. Metzger, W. J. Baltutis, K. B. Chakrabarti, S. L. Hirsch, and B. K. Laursen. 2019. A systems thinking approach for eliciting mental models from visual boundary objects in hydropolitical contexts: a case study from the Pilcomayo River Basin. Ecology and Society 24(2):9. https:// doi.org/10.5751/ES-10586-240209 